\title{
Undergraduates' Perception on the Ease and Usefulness of Electronic Information Resources
}

\author{
Mary-Colette chimereogo Ugwuja ${ }^{\text {a* Kingsley Obiora Udem }}{ }^{\mathrm{a}}$ \\ a ugwujacolette311@gmail.com \\ ${ }^{a}$ Department of library and information science, Nnamdi Azikiwe University. Awka, 420110, Nigeria
}

\begin{abstract}
This study examined undergraduates' perception on the ease and usefulness of electronic information resources in Festus Aghagbo Nwako Library. The research objectives strictly guided literatures. The research design is adopted for this study was descriptive survey design. 950 undergraduates' registered library users were used as the population of the study. At the same time, 50 undergraduates' registered library users were selected through the accidental sampling technique. A questionnaire was used to answer the research questions. After that indebt analysis, findings from the study revealed that undergraduates find electronic information resources easy to use, easy to learn, electronic information resources are helpful for research. This study recommends that; library management conduct training on the skills needed for the use of electronic information resources at the beginning of every academic session.
\end{abstract}

Keywords: Undergraduate students; Library; Electronic information resources; Descriptive survey; accidental sampling.

\section{Introduction}

Information in this new age offers possibilities for the future with information delivered in different formats. Also the potentials of the electronic network are astonishing. Education is one of the key sectors that have been profoundly transformed by the application of the technological advancement offered by the digital revolution that is rocking the globe. (Yushau,2006).

In any educational and research institution the library plays a pivotal role. An academic library according to Yusuf and (Iwu,2010) is a store house of information or a record of human experience to which users may turn to for information. The traditional library is characterized mainly with the provision of information in print format. Information is usually in form of monographs, journals, pamphlets, magazines and so on. Traditional libraries though guided by the objective of linking users who needed information to the sources that had the information had most of their work done without the use of information technology which is rather time consuming. But now this has changed for many libraries with greater use and application of 
information and communication technology (ICT). Application of information and communication technology to library and information work has revolutionized the traditional concept of libraries from store house to an intellectual information Centre, connoting the concept of electronic library. It has opened a new chapter in library operations and facilitated global access to information crossing the geographical limitations. Using ICT, libraries are also playing a very important role in facilitating access to global information and knowledge resources became available online, many university libraries are introducing electronic information resources. With the advancement of information and communication technology there is a significant growth in availability and use of electronic information resources.

Electronic information resources (EIRs) also known as electronic resources are those resources that deal with both electronic and digitized materials which can be either accessible from library's in house database or from the world-wide web. The born electronic materials includes e-books, e-journals, e-newspapers, emagazines, e-projects, e-thesis, e-dissertations, e-reports, website, and other related materials which can be considered necessary by the users, researchers, information professionals or even by the library management itself. Shariful, (2012).

\section{Literature review}

Electronic information resources was defined by (Reitz,2004) as material consisting of data and/or computer program(s) encoded for reading and manipulation by a computer, by the use of a peripheral device directly connected to the computer, such as CD.ROM device or remotely via a network, such as the internet. According to Reitz the category includes software applications, electronic texts, bibliographic databases, institutional repositories, websites, e-books, collections of e-journals, etc.

Electronic information resources are a wide range of products going from electronic periodicals to CD.ROMs, from mailing list to databases, all, having a common feature of being used and sometime modified by a computer.(Thanuskodi,2012). They are available in various forms like digital libraries, online journal, magazine, e-learning tutors and online databases, Emerald, science Direct, Academic search premier, Ebscohost, TEEEL, Oare Sciences, Hinari, Virtual Library (VL), e-books collections, e-journals covering a variety of subjects, and major bibliographic databases like AGORA and MEDLARS. Besides these, there are other collections of internet resources indexed by subjects. Also, because of the effective presentation with multimedia tools, these e-resources have become the source of information in the 21 st century.

The term electronic information resources according to( Olarongbe and Ibrahim, 2009) is taken to refer to library's information bearing materials that are in electronic form which include electronic books(e-books), electronic newspapers(e-newspapers), electronic journals as well as internet resources. These resources are 
stored electronically and made available through electronic system and computer networks. Das, Anushadhan, Odisha and Maharana, (2013) affirmed that the features of electronic information resources (EIRs) include: multiple access points, speed, rich content and timeliness. The creation of electronic information resources has no doubt, made essential impact in teaching and learning process. Some of the major benefits of electronic information resources according to (Bagudu and Sadiq 2013) include accessing resources in digital format, which allows online access to users at numerous locations at anytime and anywhere, it can be at home, in the library, in the class, laboratories e.t.c. considering the advantages, it is not surprising that most libraries endeavor to provide electronic information resources in electronic format.

Electronic information resources (EIRs) according to (Obaseki and Amune, 2009) is the presence of printed information in a format only viewed and accessed through the ICT via electrical manipulations. This assertion indicated that an electronic information resource connotes not only those information resource accessed only with the aid of computer, but also other forms of ICTs such as blackberry phones or android phones and Ipad. For any academic library to thrive in this information age, the library irrespective of the size of its collection must embrace information communication technology.

Electronic information resources are also referred to as the new wave of air blowing many libraries globally, simply because there is increasing amount of information retrieval. With electronic libraries, abstracts and indexes are available online and there is easy access to computer- held information, together with the possibility of including sound and video. Meaning that for many other reference tools, electronic format has notable advantage over print.

According to (slim,2001) electronic information resources and services can be seen as what users' access electronically via computing network from inside the library or remotely from the library. (Tammaro,2006) observed that electronic information resources include websites, online databases, e-journals, audio visual, multimedia e.t.c. Electronic information resources provide many advantages over the traditional print resources such as easy access, universal access, saving physical space, ability to linked indexing and abstracting databases, accessibility from the user's home, office or hostels irrespective of whether or not the physical library is open.

Similarly, (Kinber,1968) defines electronic information resources as the information stored in a medium which requires an electronic device to read the content. Information stored in different electronic media such as floppies, CDs, magnetic tapes, videos etc. can be retrieved with the help of other electronic devices like computers, video players etc. The electronic medium for storing information could be said to be the best as it has many advantages such as: large storage capacity, data security, space saving and easy access among others. 
An electronic resource according to (Ashikuzzaman,2014) is defined as a resource which require computer access or any electronic product that delivers a collection of data, be it text referring to full text databases, electronic journals, image collections, other multimedia products and numerical and graphical or time based commercially available title has been published with the aim to being marketed. This may be delivered on C.D ROM, on tape, via internet etc. Over the past few years, a number of techniques and related standards have been developed which allow documents to be created and distributed in electronic form. Hence to cope with the present situation, librarians are shifting towards new media, namely electronic information resources for their collection development. The e-resources on magnetic and optical media have a vast impact on the collections of university libraries. These are more useful due to internet capabilities for manipulation and searching. Providing information access is cheaper to acquiring information resources, savings and maintenance and sometimes the electronic form is the only alternative.

Ashikuzzaman also listed some characteristics of electronic information resources they include: Access to every document by anyone from anywhere. Retrieval of e- resources is quicker than print resources. The users can be guided to document by providing a link easy to search the text. In electronic environment the interaction between users and libraries is frequent.

Electronic resources are defined by AACR2, (2002) as any work encoded and made available for access through the use of a computer which includes electronic data available by: Remote access (electronic resources) refers to the use of electronic resources via computer networks. Direct access (fixed media): refers to the use of electronic resources via carriers (e.g. discsldisks, cassettes, cartridges) designed to be inserted into a computerized device or its auxiliary equipment.

The access to electronic information resources in academic libraries and among university students is rapidly increasing as a result of the massive adoption of information and communication technology. Electronic information resources in libraries are considered essential part of modern society. This is because they play a very important in education. The provision of electronic information resources and services in libraries is important to any educational program that intends to achieve objectives that is in line with the present day to day global best practices. Electronic information resources (EIR) are now recognized as being of greatest importance to academic libraries. The library is obviously the source of power and knowledge in higher education and research. The use of library is a matter of concern to students, teachers and researchers. The exponential growth of literature often creates problems for them to access appropriate literature and their use. The problem has, however considerably been resolved with the help of information and communication technology (ICT). The use of information technology for management and handling of information and data has grown significantly even in many least-developed countries despite the economic constraints. 
The use of information technology in libraries has been profoundly affecting all aspects of information acquisition, storage and transfer. Its magnificent development has dramatically changed the mode of library and information services. Computer based communications have not only widened the access to information and help establish linkages the professional colleagues and friends elsewhere, it has extensively facilitated message transmission, transfer and exchange of files and text, uploading/downloading database access interactive service, provision of bulletin boards and newsletters, job submission and execution, teleconferencing, file ordering, interlibrary loans, creating user profiles, consolidation and repacking of information for s pecific needs, dissemination of information of information and so on.(shamsul, 2017).

The present supply of electronic information resources is made of a range of products that may exist in different forms such as CD-ROMs and resources available on the internet such as online databases, web pages e.t.c and they provide library with vast resources for their user population (Gupta, 2011, Zimerman, 2010,Kapor 2010). The information in the web is structured to facilitate browsing. It provides access to quality control electronic information resources such as e-journals, e-books, e-databases e.t.c. Each technological development in library electronic Information resources during the 20th century was intended to make access to resources more direct, convenient and timely for the user.

The implementation of electronic information resources made the Library growing organism, as libraries adopted processes and recognized staff repeatedly to accommodate the changes inherent in the use of constantly changing technology. (Ojo-Igbinoba,2013) opined that electronics information resources and services in libraries become necessary because of large number of users. He also stated growth in date usage leads to error and delays when manual systems are applied. The above assertion gives concise but comprehensive explanation of the various forms of electronic information resources and services.

Thus, electronic information resources are vital, and they are currently the back bone of any dynamic collection, but most electronic information resources such as a full text databases and electronic books are not publicly available free of charge and therefore they are expensive. Today librarians are very much concern about their effective use. (Nunberg,2011) defined electronic information resources as the information stored in a medium which requires an electronic device to read its content which is in different electronic media such as tapes, floppies, radios etc. which can be retrieved with the help of other electronic devices like computers. The use of electronic information resources and services in a library also makes it possible for library staff to discover new information to develop the special gifts and talents hidden in each student, thereby assisting him/ her to build a career.

Lynch, (2000) states that electronic information resources in libraries save time and effort than resources in the manual systems. It permits access to records, facilitates wider access to information, increases access to 
resources and allows easier editing of information. He also presented the effect of electronic information resources and services on libraries in three ways:

Automation: in this phase, libraries apply a range of information technology (IT) to the management of electronic information resources. A higher stage of library automation is characterized by the conversion of print materials to electronic formats.

Networked Information: Here electronic content and services become accessible through the network anytime, anyplace and could be tailored to meet the needs and objectives of each users.

Transformation: Technological changes have resulted to a set of new issues: How to achieve digital information, how to address the question of authenticity, integrity and provenance. Similarly, Hawthorne, (2008) Indicated that the pursuit of electronic information resources by libraries was driven by the core values of library science. It is possible to recognize in Ranganathan's five laws of library science, the motivation that drove libraries to incorporate electronic resource into services and collections. Paraphrased to better suit electronic resources, the laws read; resources are for use, every person his or her resource, every resource its user, save the time of the user, and the library is a growing organism (Ranganathan, 1963).

\section{Area of study}

The study was carried out in Festus Aghagbo Nwako Library, Nnamdi Azikiwe university, Awka in Anambra State of Nigeria. The population of this study comprises of 950 students who are registered users in Prof. Festus Aghagbo Nwako library in Nnamdi Aikiwe university Awka for the period of June,july, August, 2017.

\section{Methodology}

Several methods where adopted for this research; this methods range administering the instruments and method adopted for data analysis. The population of this study comprises of 950 students who are registered users in Prof. Festus Aghagbo Nwako library in Nnamdi Aikiwe university Awka for the period of June, July, August,2017. The sample of the study is 50 students selected through accidental sampling. The instrument employed for the study was a questionnaire. The questionnaire which is used to ascertain undergraduate's perception on the ease and usefulness of electronic information resources in Festus Aghagbo Nwako was used to collect data on the research questions which guided the study. The instrument was personally administered to the respondents. This ensured some interaction between the respondent and the researcher. The distribution and collection was done by hand minimize the chances of loss and damage. The questionnaires were later collected and a total number of 48 questionnaires were collected. This constitutes $96 \%$ of the questionnaire 
distributed. Data obtained in the study were analyzed using descriptive statistics (arithmetic mean and simple percentage).

Research question: What is undergraduates' perception on the ease and usefulness of electronic information resources? The research question is by questionnaire and through in-depth interview. The findings are shown in table 1 and 2 respectively.

\section{Result and discussion}

Table 1 shows that all the questions appear to have mean score of 2.5 and above. This shows that undergraduates of Nnamdi Azikiwe university agreed that: electronic information resources are easy to use; electronic information resources are easy to learn; intention to use digital library play an important role in producing future usage of e-resources; user intensity to use e-resources are largely influenced by behavior; easy access results to high usage of electronic information resources; there are difficulties encountered in using electronic information resources; inaccessibility of electronic information resources affects usage; there are difficulties in accessing electronic information resources.

Table no 1: Mean ratings on undergraduates' perception on the ease and usefulness of electronic information resources.

\begin{tabular}{|c|c|c|c|}
\hline $\mathbf{S} / \mathbf{N}$ & Questions & $\mathbf{X}$ & Decision \\
\hline 1 & Electronic Information Resources are easy for use & 3.08 & Agreed \\
\hline 2 & Electronic Information Resources are easy to learn & 3.46 & Agreed \\
\hline 3 & $\begin{array}{l}\text { Intention to use digital library play an important role in predicting } \\
\text { future usage of electronic information resources }\end{array}$ & 3.52 & Agreed \\
\hline 4 & User intensity to use e-resources is largely influenced by behavior & 2.56 & Agreed \\
\hline 5 & $\begin{array}{l}\text { Easy access results to high usage of electronic Information } \\
\text { resources }\end{array}$ & 2.70 & Agreed \\
\hline 6 & $\begin{array}{l}\text { There are difficulties encountered in using electronic information } \\
\text { resources }\end{array}$ & 2.90 & Agreed \\
\hline 7 & Inaccessibility of electronic information resources affects usage & 3.44 & Agreed \\
\hline 8 & Electronic information resources are not useful to undergraduates & 3.10 & Agreed \\
\hline
\end{tabular}


Table 2 represents undergraduates' perception on the ease of use of electronic information resources. Undergraduates using the mean rating of 2.5 and above accepted that: electronic information are useful for research; Electronic Information Resources has the ability to search multiple files at the same time; Electronic information resources have the ability to access documents from outside the library; Electronic information provides access to information restricted to the user due to geographical location; Electronic information resources are used for current awareness services; Electronic information resources are used for selective dissemination of information; Electronic information resources are not useful to undergraduates; Electronic information resources do not improve the academic performance of undergraduates. While mean ratings below 2.5 were rejected which states electronic information resources are not useful to undergraduates and electronic information resources do not improve the academic performance of undergraduates.

Table no 2: Undergraduate's perception on usefulness of electronic information resources

\begin{tabular}{|c|c|c|c|}
\hline $\mathbf{S} / \mathbf{N}$ & Questions & $\mathbf{X}$ & Decision \\
\hline 1 & Electronic information resource is useful for research & 3.10 & Agreed \\
\hline 2 & $\begin{array}{l}\text { Electronic information resource has the ability to search multiple } \\
\text { files at the same time }\end{array}$ & 3.56 & Agreed \\
\hline 3 & $\begin{array}{l}\text { Electronic information resource compliments the printed resources } \\
\text { that are based on the traditional library }\end{array}$ & 2.70 & Agreed \\
\hline 4 & $\begin{array}{l}\text { Electronic information resources have the ability to access } \\
\text { documents from outside the library }\end{array}$ & 3.20 & Agreed \\
\hline 5 & $\begin{array}{l}\text { Electronic resource provide access to information restricted to the } \\
\text { user due to geographical location }\end{array}$ & 3.00 & Agreed \\
\hline 6 & Electronic resources are used for current awareness services & 3.44 & Agreed \\
\hline 7 & $\begin{array}{l}\text { Electronic resources are used for selective dissemination of } \\
\text { information }\end{array}$ & 3.46 & Agreed \\
\hline 8 & Electronic information resources are not useful to undergraduates & 2.24 & Disagreed \\
\hline 9 & $\begin{array}{l}\text { Electronic information resources do not improve the academic } \\
\text { performance of undergraduates }\end{array}$ & 2.44 & Disagreed \\
\hline
\end{tabular}

\section{Conclusion}

In conclusion, undergraduates accepted electronic information resources to be easy to use. It was also concluded by undergraduates that electronic information resources are useful and will help to improve the academic performance of undergraduates in universities.

The library management should ensure they conduct training on the skills needed for the use of electronic 
information resources at the beginning of every academic session. They should also employ more IT staff in the library that can assist the students when they encounter problems while using the electronic information resources.

There should be adequate electricity supply, adequate network and information overload, affordable cost of access, adequate electronic information resources, less difficulty in accessing electronic information resources, provision of technical support staff, effective information retrieval skills, adequate computer system and facilities.

There should be improved public relations between staff and students in the Library as this will help the staff to understand the information needs of students, the electronic information resources needed by students and so provide better services to users (undergraduates).

\section{References}

Bagudu, A.A. \& Sadiq, H. (2013). Students perception of digital library services: A case study of international Islamic university, Malaysia.

Gupta, D. K (2011). Use pattern of print and electronic journals at the Kurukshetra University India. Program: Electronic library and information systems 45(2):213-230. https://doi.org/10.1108/00330331111129741.

Hawthorns, D. (2008). History of Electronic Resources. PP. 1-15 in Yu and Breivold.

Kapoor, K. (2010). Print and electronic resources usage statistics at Guru Gobond sing indraprasta university library. Program: Electronic library and information systems 44(1)59-68.

Kinber, R. T. (1968). Electronics in Libraries 2nd ed. New. York. Vol to pergamon press.

Lynch, C. A. (2008). From Automation to Transformation: Forty years of Library and information Technology in higher Education.

Nunberg, (2014). use of electronic information sources by postgraduate students in Nigeria. Influencing factors library philosophy and practice.

Obaseki, T. I. \& Amune, J. B. (2009). Electronic resources: avenue for information resources acquisition in the 21 st century Nigeria tertiary institutions. A paper presented at the AGM of NLA Cross River state Chapter Conference. At UNICAl Conference hotel Calabar 9-11 november.

Ofo-igbinoba, M. E. (2008). The practice of conservation of library materials in sub-saharan Africa. Indiana. Africa studies program, Indiana university.

Olarongbe, S. A. \& Ibrahim, D.M. (2009). The use of electronic resources by Academic staff at the university of Illorin, Nigeria.

Rectz, J. M. (2004). Online dictionary of library and information science. Retrieved January28, 2016 form 
http://Lu.com/odlid/index.cfm.

Shariful, I. (2012). definition of digital information resources. Accessed from https:univdhaka.academia.edu/Sharifulislam/papers/20383./definitionofdigitalinformationresources.

Slim, (2001). Measure and statistics for research libraries networked services procedures and issues. International Journal of Library and Information Services. 54(1): 2004.

Tammaro, A. M. (2006). The digital Library Users. Case study on needs expectations and skills.

Thanuskodi, S. (2012). Use of e-resources by the students and researchers of faculty of arts, Annamalai University. Retrieved from http://article.supub.org/10.5923.1.library,20120101.01.html.

Yushau, B. (2006). Computer altitude, use, experience, software familiarity and perceived pedagogical usefulness: the case of mathematics science and technology. Education, 2(3).

Zimeran, M. (2010). Periodicals: Print or electronic? New library world. 111(9/10):426-433.

$[1]$. 